\title{
Team Science and Accelerated Vaccine Introduction in Cuba: A View from the Pneumococcal Project
}

\author{
Nivaldo Linares-Pérez MD MS PhD
}

Translated from Spanish and reprinted with permission from Revista Cubana de Salud Pública Vol 44 No 2, Apr-Jun 2018.

Original available from: http://www.revsaludpublica.s/d.cu/index.php/spu/article/view/1065

\begin{abstract}
The process of research and evaluation of new products and technologies requires a combination of transdisciplinary theoretical and methodological approaches for managing and achieving objectives. The research, development and evaluation strategy of the new Cuban pneumococcal vaccine combines the approaches of team science and accelerated vaccine introduction. These frameworks are proposed for discussions regarding biotech product evaluation, using their application to the Pneumococcus Project as an example. Emphasis is on the use of team science to eliminate obstacles to obtaining a product of great scientific and technological complexity while establishing robust scientific evidence to support its use and marketing. All of this is in support of opportune and efficient decisions for accelerated introduction of new vaccines in Cuba.
\end{abstract}

KEYWORDS Team science, vaccines, pneumococcal conjugate vaccine, Cuba

The most recent Cuban pneumococcal conjugate vaccine from the Finlay Vaccine Institute (IFV) marks another milestone in Cuban vaccinology (Galindo, 2015, personal communication). The research, development and evaluation strategies use the perspective of two approaches: team science[1] and accelerated vaccine introduction,[2] both adapted to the Cuban context. As reported in several national[3] and international publications,[4] Cuban clinical trials to date have demonstrated satisfactory safety and immunogenicity.[5-7]

Team science is a collaborative and multidisciplinary approach that involves bringing together scientific partners, manufacturers and managers to work toward a shared purpose or objective.[1] From the start, this has been the case with the Pneumococcus Project for research, development, evaluation, production and rapid introduction of the new vaccine after its registration in Cuba. The effort entails the combination of public financing from the Cuban government, available through the Fund for Science $(\mathrm{FONCl})$, and the Finlay Vaccine Institute, of the BioCubaFarma Business Group, with technical assistance from the National Health System, such as the Pedro Kourí Tropical Medicine Institute (IPK); the National School of Public Health (ENSAP); the Provincial Health Services (SPS) of Cienfuegos, Havana and Santiago de Cuba; and the Ministry of Public Health (MINSAP) national programs.[8]

Although Cuba has not yet introduced pneumococcal vaccination, mainly due to the high cost of vaccines available in the international market, the Pneumococcus Project was designed to reduce the usual delays in new vaccine introduction; address the prevalent lack of appreciation of vaccine's value as a health technology; maximize the strengths of health services where vaccines are evaluated and applied; and capitalize on interest in and political will for the vaccine's development.

The approach of accelerated vaccine introduction[2] has been applied in the Pneumococcus Project since its inception in 2006. Institutional efforts to support development of the new vaccine, have provided a strategy that can be applied to other new vaccines, to help accelerate procedures concerning:

1. raising awareness of the need for evidence on preventable health problems after vaccine introduction;

2. clinical, epidemiological and impact evaluation research to answer key questions that support the vaccine's use and longterm sustainability; and

3. national, territorial and local coordination to ensure successful introduction in Cuba's National Immunization Program.

Scientific evidence on safety, immunogenicity, efficacy, and the direct and indirect effects of pneumococcal conjugate vaccines (PCV)—especially PCV7, PCV10 and PCV13 - has been reviewed by various groups of researchers from different parts of the world. There is consensus on vaccine safety in children and infants,[9] immunogenicity depending on the various schedules used,[10] the effect of different vaccination schedules on nasopharyngeal colonization,[11] effectiveness of different vaccination schedules in reducing invasive pneumococcal disease in diverse target populations, $[12,13]$ indirect effects on pneumococcal disease and carrier status in unvaccinated populations,[14] differential impact of vaccine administration in different regions and in presence of covariates associated with PCV immunogenicity[15] in older pediatric age groups in low- and middle-income countries,[16] and the cost-effectiveness of pneumococcal vaccination in the pediatric population of middle-income countries.[17]

The new vaccine has been designed to be used in Cuba and in other countries, following a closed-loop development model (research, development, evaluation, production and marketing), committed, as much as possible, to its accelerated introduction despite the complex process of technological application, concerns about long-term availability, restrictions on supply of necessary materials, and scarce evidence on the burden of disease associated with pneumococcal infection (due to difficulties in microbiological, clinical and epidemiological surveillance). Surveillance is essential to establish a baseline and monitor changes in effectiveness and impact on the health of Cuba's pediatric population after introduction.

Impacts expected from the Pneumococcus Project include academic, technological, social and economic results. However, the main contribution of this project is undoubtedly social, since 
the vaccine's introduction in the National Vaccination Program will reduce morbidity and mortality caused by invasive pneumococcal diseases, as well as by other associated [noninvasive-Eds.] diseases in the Cuban pediatric population. Adults aged >65 years and other unvaccinated population groups will also be indirectly protected. The knowledge generated in terms of basic and applied research will enable new conjugate vaccine projects in the near future. From an economic point of view, this will affect ability to produce the vaccine under Good Practice conditions. The conjugate vaccine can be a source of export earnings for Cuba.

Team science and accelerated vaccine introduction[2] approaches in the development of the new vaccine have contributed to development of great technical experience in the fields of basic research, pharmaceutical and technological development, clinical and health impact assessment, sanitary regulations, and production. They lay the foundation for obtaining sanitary and manufacturing licenses. The Pneumococcus Project has made progress in eliminating obstacles to obtaining the most scientifically and technologically complex vaccine yet developed in Cuba, as well as in generating the safety, efficacy and costeffectiveness evidence required for registration and marketing of this novel product and for health authorities' decision-making on its introduction in Cuba.[8]

\section{ACKNOWLEDGMENTS}

We are indebted to the scientific and professional staff of IFV, IPK, ENSAP and the Sentinel Network for Vaccine Research, Surveillance and Impact Evaluation who participated in the Pneumococcus Project, especially in research and development and strategies for surveillance \& evaluation. $-1 /$ -

\section{REFERENCES}

1. Michelle LB, Howard G, Levine-Finley S. (2010) Collaboration and Team Science: A Field Guide. Bethesda, USA: National Institute of Health; 2010.

2. Rana Hajjeh. Accelerating introduction of new vaccines: barriers to introduction and lessons learned from the recent Haemophilus influenzae type b vaccine experience. Phil Trans R Soc B. 2011;366:2827-32.

3. Linares-Pérez N, Toledo-Romaní ME, Casanova MF, Paredes B, Váldes-Balbín Y, SantanaMederos D, García-Rivera D, Toraño G, Dotres $\mathrm{CP}$, Puga R, Verez-Bencomo V. La nueva vacuna cubana antineumocócica, de las evidencias científicas disponibles, a la estrategia de evaluación clínica y de impacto. Rev Cubana Pediatr. 2017;89(sup). Acceso: 20/10/2017. Disponible en: http://www.revpediatria.sld.cu/ index.php/ped/issue/view/7

4. Linares-Pérez, N, Toledo-Romaní M, SantanaMederos D, García-Fariñas A, García-Rivera D, Valdés-Balbín Y, Vérez-Bencomo V. From individual to herd protection of pneumococcal vaccines: The contribution of Cuban PCVs implementation strategy. IJID. En prensa. Disponible online 28 April 2017: http:// www.sciencedirect.com/science/article/pii/ S1201971217300942

5. González N, Paredes B, Pérez S, Mirabal M, Rivero I, González C, et al. Safety and immunogenicity of Cuban antipneumococcal conjugate vaccine PCV7-TT in healthy adults. MEDICC Review. 2015;17(4):32-7.

6. Dotres CP, Puga R, Ricardo Y, Brono CR, Paredes B, Echemendía V, et al. Safety and preliminary immunogenicity of Cuban pneumococcal conjugate vaccine candidate in healthy children: A randomized phase I clinical trial. Vaccine. 2014;32(41):5266-70.

7. Dotres $\mathrm{CP}$, Linares-Pérez N, Toledo-Romaní ME, Puga R, Ricardo Y, Brono CR, Paredes B, et al. Safety and immunogenicity of the Cuban heptavalent pneumococcal conjugate vaccine in healthy infants. Results from a double-blind randomized control trial Phase I. Vaccine Journal En prensa 2017.

8. Linares-Pérez N. Introducción de la vacunación antineumocócica, un proyecto conjunto de la Biotecnología y el Sistema de Salud Cubano. Rev Cubana Pediatr. 2017;89(sup). Disponible en: http://www.revpediatria.sld.cu/index.php/ped/ issue/view/7

9. Thompson A, Gurtman A, Patterson S, Juergens C, Laudat F, Emini EA, et al. Safety of 13-valent pneumococcal conjugate vaccine in infants and children: meta-analysis of 13 clinical trials in 9 countries. Vaccine. 2013;31(45):5289-95.

10. Knoll MD, Park DE, Johnson TS, Chandir S, Nonyane BAS, Conklin L, et al. Systematic review of the effect of pneumococcal conjugate vaccine dosing schedules on immunogenicity. The Pediatric Infectious Dis J. 2014;33(suppl 2):S119.

11. Fleming-Dutra KE, Conklin L, Loo JD, Knoll MD, Park DE, Kirk J, et al. Systematic review of the effect of pneumococcal conjugate vaccine dosing schedules on vaccine-type nasopharyngeal carriage. The Pediatric Infectious Dis $\mathrm{J}$. 2014;33(suppl 2):S152.

12. Conklin L, Loo JD, Kirk J, Fleming-Dutra KE, Knoll MD, Park DE, et al. Systematic review of the effect of pneumococcal conjugate vaccine dosing schedules on vaccine-type invasive pneumococcal disease among young children. Pediatric Infectious Dis J. 2014;33(suppl 2):S109.

13. Black $S$, Shinefield $H$, Fireman B, Lewis $E$, Ray P, Hansen JR, et al. Efficacy, safety and immunogenicity of heptavalent pneumococca conjugate vaccine in children. Pediatric Infectious Dis J. 2000;19(3):187-95

14. Loo JD, Conklin L, Fleming-Dutra KE, Knoll $M D$, Park DE, Kirk J, et al. Systematic review of the indirect effect of pneumococcal conjugate vaccine dosing schedules on pneumococcal disease and colonization. Pediatric Infectious Dis J. 2014a;33:S161-71.

15. Park DE, Johnson TS, Nonyane BAS, Chandir $\mathrm{S}$, Conklin L, Fleming-Dutra KE, et al. The differential impact of coadministered vaccines, geographic region, vaccine product and other covariates on pneumococcal conjugate vaccine immunogenicity. Pediatric Infectious Dis J. 2014;33(suppl 2):S130.

16. Bonner K, Welch E, Elder K, Cohn J. Impact of Pneumococcal Conjugate Vaccine Administration in Pediatric Older Age Groups in Low and Middle Income Countries: A Systematic Review. PloS one. 2015;10(8):e0135270.

17. Nakamura MM, Tasslimi A, Lieu TA, Levine $O$, Knoll MD, Russell LB, et al. Cost effectiveness of child pneumococcal conjugate vaccination in middle-income countries. Int Health. 2011;3(4):270-81.

\section{THE AUTHOR}

Nivaldo Linares-Pérez (nlinares@finlay.edu .cu), Finlay Vaccine Institute, Havana, Cuba. 